\title{
FACTORS AND ESTIMATION OF RISK FOR CARDIOVASCULAR DISEASES AMONG PATIENTS IN PRIMARY HEALTH CARE IN CENTRAL SERBIA
}

\author{
Bojan Đokić2 ${ }^{\text {, Nela Đonović1, }}$, Bojana Tadić ${ }^{3}$, Divna Nikolić ${ }^{4}$ \\ ${ }^{1}$ Public Health Institute Kragujevac, Serbia \\ ${ }^{2}$ Faculty of Medical Sciences, University of Kragujevac, Kragujevac, Serbia \\ ${ }^{3}$ Health Centre "Danica i Kosta Šamanović", Knić, Serbia \\ ${ }^{4}$ Health Centre, Kragujevac, Serbia
}

\begin{abstract}
SUMMARY
Aim: Cardiovascular diseases present major cause of morbidity and mortality in the world as well as in Central Serbia. The aim of this study is to analyze the frequency of risk factors and estimate risk for the development of cardiovascular diseases.

Methods: The database was collected from health records of the Health Centre in Kragujevac. The following parameters were observed: gender and age, smoking, anthropometrical measurements and Body Mass Index, the value of systolic and diastolic blood pressure, diabetes, levels of cholesterol, and triglycerids in blood serum. The estimation of risk for developing the fatal cardiovascular disease during the period of ten years is determined according to SCORE system model. The statistical package SPSS version 18.0 was used for the statistical analysis.

Results: The study sample consisted of 1,053 people, 505 men and 548 women. $68.8 \%$ of people were overweight and obese, arterial hypertension was noted in $72.6 \%$, and diabetes type II in $13.3 \%$ of people. $67.6 \%$ of people had a high level of total cholesterol in blood serum and $39.6 \%$ of people had a high level of triglycerids in blood serum. The metabolic syndrome was noted in $44.3 \%$, and 3 or more risk factors for cardiovascular disease were noted in $65 \%$ of the population. We determined a significant statistic difference for age, smoking, nutritional status, dyslipidemia, and diabetes.

Conclusion: The high incidence of potentially modifiable risk factors for cardiovascular disease gives a possibility to apply prevention measures for promotion and preservation of health.
\end{abstract}

Key words: risk factors, cardiovascular disease, prevention

Address for correspondence: B. Đokić, University of Kragujevac, Faculty of Medical Sciences, Milivoja Živanovića 3/13, 34000 Kragujevac, Serbia. E-mail: bbojandj@yahoo.com

\section{INTRODUCTION}

Cardiovascular diseases present a major cause of morbidity and mortality in the world as well as in Central Serbia. It is a large public health problem because cardiovascular diseases may cause disablement. More than the third of deaths among middle aged people are caused by cardiovascular diseases (1).

According to the database of the World Health Organization, 17 million of deaths in the whole world are caused by cardiovascular diseases annually (2).

Atherosclerosis, as the main pathology process for diseases of coronary and cerebral blood vessels, is encouraged by using tobacco, unhealthy nutrition and physical inactivity, hypertension, dyslipidemia, and diabetes (3).

The primary health care insists on early identification of patients with high risk for developing cardiovascular diseases. The main reason is to preserve health by applying suitable measure on time.

This study focuses on modifiable risk factors like: hypertension, smoking, nutritional status, diabetes and increased level of cholesterol, and triglycerids in blood serum.

The aim of this research is to analyze the frequency of risk factors and to estimate the risk for the development of cardiovascular diseases in the population under study.

\section{MATERIALS AND METHODS}

This epidemiological study included patients aged 40-65 years, who had periodical medical check-ups conducted in the period between 1 March and 30 September 2013. The data were collected during this time period from medical records of the Health Centre of Kragujevac located in the city centre. The following parameters were monitored: gender, age, smoking habits, anthropometrical measures, and Body Mass Index, systolic and diastolic blood pressure, diabetes, cholesterol, and triglyceride levels. The subjects were divided into the following age categories: $40-49$ years old, 50-59 years old and more than 60 years old.

We observed the following anthropometrical parameters: body height, body weight and waist circumference. Body Mass Index (BMI) was used for estimating the degree of nutritional status. The World Health Organization suggests these parameters: $\leq 18.4 \mathrm{~kg} / \mathrm{m}^{2}$ underweight, $18.5-24.9 \mathrm{~kg} / \mathrm{m}^{2}$ normal BMI, 25-29.9 $\mathrm{kg} / \mathrm{m}^{2}$ overweight, $30-34.9 \mathrm{~kg} / \mathrm{m}^{2}$ obesity level I, $35-39.9 \mathrm{~kg} /$ $\mathrm{m}^{2}$ obesity level II and $\geq 40 \mathrm{~kg} / \mathrm{m}^{2}$ massive obesity. We used the waist circumference as a parameter to identify the level of fat. WHO recommends the following waist measures: 95-102 cm for men and $81-88 \mathrm{~cm}$ for women at increased risk, and the waist circumference over $102 \mathrm{~cm}$ for men and over $88 \mathrm{~cm}$ for women 
correspond to the very high risk for metabolic complications of obesity.

We monitored the following biochemical parameters: cholesterol and triglycerids, whose higher level can significantly contribute to the development of cardiovascular diseases. The guidelines of the national clinical practice suggest that a desirable total cholesterol level should be below $5.2 \mathrm{mmol} / \mathrm{l}$, while the levels of 5.2-6.19 mmol/1 and more than $6.2 \mathrm{mmol} / \mathrm{l}$ correspond to high levels and high-risk levels, respectively. The levels of triglycerids should be below $1.7 \mathrm{mmol} / 1$, the levels from $1.7-2.29 \mathrm{mmol} / \mathrm{l}$ and the levels exceeding $2.30 \mathrm{mmol} / \mathrm{l}$ are considered high and very high, respectively.

We noted the records that include patients with hypertension and the levels of systolic and diastolic blood pressure with regular monthly check. According to the national clinical practice guidelines, the targeted blood pressure in treated hypertensive patients should be 140/90 mmHg, and these levels of hypertension indicated how to divide patients into two groups: the group of well regulated hypertension, and the group with the poorly regulated, with a pressure of 140-159/90-99 mmHg; 160-179/100-109 $\mathrm{mmHg}$; over 180/over $110 \mathrm{mmHg}$; the isolated systolic hypertension with a systolic pressure is predicted above $140 \mathrm{mmHg}$ and diastolic below $90 \mathrm{mmHg}$.

We made reports of the patients with the metabolic syndrome. This syndrome was determined according to the following criteria: abdominal obesity (waist circumference greater than $102 \mathrm{~cm}$ for men and greater than $88 \mathrm{~cm}$ for women), triglycerids higher than $1.7 \mathrm{mmol} / \mathrm{l}$, HDL cholesterol lower than $1.0 \mathrm{mmol} / \mathrm{l}$ for men and lower than $1.3 \mathrm{mmol} / \mathrm{l}$ for women, blood tension higher than $130 / 85 \mathrm{mmHg}$, and presence of glucose intolerance. Three of the five criteria were required for diagnosis.

Individual assessments of the ten-year risk of fatal cardiovascular diseases were determined according to the Systematic Coronary RISC Evaluation system (SCORE). We noted the following facts: the low risk with a score less than $4 \%$, the moderate risk with $4-5 \%$, the high risk with $5-8 \%$, and the very high risk with levels above $8 \%$.

We used objective statistical and mathematical methods for the statistical analysis of the data, and the type of data and statistical tests followed. The database was created in the statistical package SPSS ver. 18.

\section{RESULTS}

This epidemiological study included 1,053 people, 505 men and 548 women in the city of Kragujevac with the average age of $55.65 \pm 8.272$ years. All the examinees were from the urban area of the city of Kragujevac. BMI showed the following results: 18 (1.7\%) were underweight, $310(29.4 \%)$ of normal weight, 438 (41.6\%) overweight, 225 (21.4\%) with the first degree obesity, 52 (4.9\%) with the obesity of the second degree, and 10 (0.9\%) were of massive obesity. BMI was not statistically significant between men and women $\left(\chi^{2}=10.699, p=0.058\right)$. The older patients had higher prevalence of overweight and obesity: 153 (60.5\%) subjects aged $40-49$ years, $238(66.7 \%)$ subjects aged $50-59$ years, and 334 (75.4\%) over 60 years of age. This proved to be statistically significant $\left(\chi^{2}=67.89, \mathrm{p}<0.05\right)$. There were $134(46.4 \%)$ patients who did not suffer from hypertension, but had a normal weight, compared to 106 (24.3\%) well-regulated hypertensive patients with normal BMI and only 70 (21.3\%) with normal BMI among poorly regulated hypertensive patients (Table 1 ). The patients with overweight, obesity I, II and III also suffered more from diabetes compared to those with normal weight $\left(\chi^{2}=30.686, \mathrm{p}<0.001\right)$ (Table1). The increased triglycerides levels (over $1.7 \mathrm{mmol} / \mathrm{l}$ ) were present in up to $337(80.6 \%)$ subjects with BMI $\geq 25 \mathrm{~kg} /$ $\mathrm{m}^{2}$ compared to the subjects with normal nutrition $-79(18.9 \%)$. This is statistically significant difference $\left(\chi^{2}=158.5, \mathrm{p}<0.05\right)$. The increased total of cholesterol was also significantly higher in the obese and overweight patients than in normal weight subjects (70.8\% vs. $\left.28.4 \%, \chi^{2}=128.12, \mathrm{p}<0.05\right)$.

Central fat distribution was determined by waist size, and the results show that 317 (30.1\%) subjects had normal waist circumference, in $287(27.3 \%)$ the increased waist size was found out, and in 449 (42.6\%) subjects highly increased waist circumference was associated with an increased risk of metabolic complications of obesity. There is no significant difference in the increased waist circumference in both men and women $\left(\chi^{2}=1.96, \mathrm{p} \geq 0.05\right)$. The increased waist circumference was detected in $122(85.9 \%)$ patients with diabetes compared to only 20 (14\%) diabetics with normal waist circumference $\left(\chi^{2}=73.26, \mathrm{p}<0.05\right)$.

In this sample, the prevalence of smoking was $35.9 \%$ (378). Smokers were more frequent in the category of younger patients: 40-49 years 125 (49.4\%), 50-59 years 147 (41.2\%) compared to

Table 1. BMI in relation to hypertension and diabetes $(N=1,053)$

\begin{tabular}{|c|c|c|c|c|c|c|c|}
\hline & \multicolumn{6}{|c|}{ BMI $\left(\mathrm{kg} / \mathrm{m}^{2}\right)$} & \multirow[b]{2}{*}{$\mathrm{p}$-value } \\
\hline & $\begin{array}{l}\text { Underweight } \\
\quad(<18.4) \\
N=18(1.7 \%)\end{array}$ & $\begin{array}{c}\text { Normal } \\
(18.5-24.9) \\
N=310(29.4 \%)\end{array}$ & $\begin{array}{c}\text { Overweight } \\
\text { (25-29.9) } \\
\mathrm{N}=438(41.6 \%)\end{array}$ & $\begin{array}{c}\text { Obesity I } \\
(30-34.9) \\
\mathrm{N}=225(21.4 \%)\end{array}$ & $\begin{array}{c}\text { Obesity II } \\
(35-39.9) \\
N=52(4.9 \%)\end{array}$ & $\begin{array}{c}\text { Obesity III } \\
\quad(\geq 40) \\
N=10(0.9 \%)\end{array}$ & \\
\hline Without hypertension & $12(66.7 \%)$ & $134(43.2 \%)$ & $91(20.8 \%)$ & $42(18.7 \%)$ & $9(17.3 \%)$ & $1(10.0 \%)$ & $<0.001$ \\
\hline Well regulated hypertension & $4(22.2 \%)$ & $106(34.2 \%)$ & $210(47.9 \%)$ & $92(40.9 \%)$ & $19(36.5 \%)$ & $5(50.0 \%)$ & 0.003 \\
\hline $140-159 / 90-99 \mathrm{mmHg}$ & $0(0 \%)$ & $15(4.8 \%)$ & $28(6.4 \%)$ & $17(7.6 \%)$ & $5(9.6 \%)$ & $1(10.0 \%)$ & 0.527 \\
\hline $160-179 / 100-109 \mathrm{mmHg}$ & $1(5.6 \%)$ & $23(7.4 \%)$ & $53(12.1 \%)$ & $35(15.6 \%)$ & $12(23.1 \%)$ & $2(20.0 \%)$ & 0.003 \\
\hline$\geq 180 / \geq 110 \mathrm{mmHg}$ & $0(0.0 \%)$ & $5(1.6 \%)$ & $10(2.3 \%)$ & $8(3.6 \%)$ & $0(0.0 \%)$ & $0(0.0 \%)$ & 0.513 \\
\hline$\geq 140 / \leq 90 \mathrm{mmHg}$ & $1(5.6 \%)$ & $27(8.7 \%)$ & $46(10.5 \%)$ & $31(13.8 \%)$ & $7(13.5 \%)$ & $1(10.0 \%)$ & 0.488 \\
\hline Without diabetes & $18(2.0 \%)$ & $283(31.1 \%)$ & $382(41.9 \%)$ & $186(20.4 \%)$ & $35(3.8 \%)$ & $7(0.8 \%)$ & \multirow{2}{*}{$<0.001$} \\
\hline With diabetes & $0(0.0 \%)$ & 27 (19.0\%) & $56(39.4 \%)$ & $39(27.5 \%)$ & $17(12.0 \%)$ & $3(2.1 \%)$ & \\
\hline
\end{tabular}


Table 2. Metabolic syndrome in relation to age, hypertension and nutritional status

\begin{tabular}{|c|c|c|c|c|}
\hline & With metabolic syndrome & Without metabolic syndrome & $x^{2}$ & $\mathrm{p}$-value \\
\hline \multicolumn{5}{|l|}{ Age } \\
\hline 40-49 years & $71(28.1 \%)$ & $182(71.9 \%)$ & \multirow{3}{*}{47.315} & \multirow{3}{*}{$<0.001$} \\
\hline $50-59$ years & $153(42.9 \%)$ & $204(57.1 \%)$ & & \\
\hline Over 60 years & $243(54.9 \%)$ & $200(45.1 \%)$ & & \\
\hline With hypertension & $431(56.4 \%)$ & $333(43.58 \%)$ & \multirow{2}{*}{179.453} & \multirow{2}{*}{$<0.001$} \\
\hline Without hypertension & $36(12.5 \%)$ & $253(87.5 \%)$ & & \\
\hline Normal BMI & $54(17.4 \%)$ & $256(82.6 \%)$ & \multirow{2}{*}{193.151} & \multirow{2}{*}{$<0.001$} \\
\hline Obesity BMI $\geq 30 \mathrm{~kg} / \mathrm{m}^{2}$ & $207(72.1 \%)$ & $80(27.9 \%)$ & & \\
\hline
\end{tabular}

Table 3. Assessment of the ten year risk of fatal cardiovascular disease according to gender

\begin{tabular}{|l|c|c|c|c|}
\hline & Low & Moderate & High & Very high \\
\hline Male & $199(39.4 \%)$ & $43(8.5 \%)$ & $124(24.6 \%)$ & $139(27.5 \%)$ \\
\hline Female & $397(72.4 \%)$ & $49(8.9 \%)$ & $83(15.1 \%)$ & $19(3.5 \%)$ \\
\hline
\end{tabular}

$X^{2}=163.947, p<0.001$

older patients over 60 years where smoking was reported in 106 $(23.9 \%)$ patients $\left(\chi^{2}=6.68, \mathrm{p}<0.05\right)$. The uncontrolled hypertension was more frequent among smokers than non-smokers (47.9\% vs. $\left.40.6 \%, \chi^{2}=29.240, \mathrm{p}<0.05\right)$.

The reported frequency of diabetes in this sample was $13.5 \%$ (142), and the metabolic syndrome prevalence was $44.3 \%$ (467). The metabolic syndrome prevalence according to the age groups was as follows: 243 (54.9\%) patients aged 60 years and over, 153 (42.9\%) patients aged 50-59 years, and a group of $71(28.1 \%)$ patients aged $40-49$ years, which was statistically significant $\left(\chi^{2}=95.07, p<0.05\right)$ (Table 2$)$. No statistically significant difference was found among genders of the respondents with regard to metabolic syndrome $\left(\chi^{2}=0.644, p=0.422\right) .56 .4 \%$ of hypertensive patients had metabolic syndrome compared to $12.5 \%$ of the subjects without hypertension. This proved to be statistically significant $\left(\chi^{2}=334.1, \mathrm{p}<0.05\right)$ (Table 2$)$. Metabolic syndrome was present in $207(72.1 \%)$ obese patients with BMI $\geq 30 \mathrm{~kg} / \mathrm{m}^{2}$ and in 124 (87.3\%) diabetic patients (Table 2).

The mean systolic blood pressure in the analyzed sample was $135.39 \pm 17,215 \mathrm{mmHg}$, and the mean diastolic blood pressure was $81.40 \pm 8,639 \mathrm{mmHg}$. The prevalence of hypertension in this sample was $72.6 \%$ (764), the number of well-regulated hypertensive patients taking antihypertensive therapy was 436 (57.1\%), and the number of patients with poorly regulated blood pressure was 328 (42.9\%). No significant gender differences in hypertensive patients included in the sample were shown $\left(\chi^{2}=10.455, \mathrm{p}=0.063\right)$.

66 (50.4\%) patients with diabetes had blood tension well regulated, and 65 (49.6\%) had blood tension poorly regulated. There were no statistically significant differences $\left(\chi^{2}=0.008, p \geq 0.05\right)$.

The mean value of total cholesterol level in the test sample was $5.81 \pm 1.2 \mathrm{mmol} / \mathrm{l}$ and mean triglyceride level was $1.72 \pm 1.4$ $\mathrm{mmol} / \mathrm{l}$. Desirable total cholesterol had 341 (32.4\%) patients, borderly high cholesterol 333 (31.6\%) patients, and high-risk levels 379 (36.0\%) patients. 306 (60.6\%) men had higher levels of total cholesterol versus 406 (74.1\%) women with increased total cholesterol, the statistically significant difference was $\left(\chi^{2}=348.00\right.$, $\mathrm{p}<0.05)$. Desirable triglyceride values had $635(60.3 \%)$, borderly high 209 (19.8\%), and high-risk level 209 (19.8\%) patients. No significant differences in triglyceride levels were shown between genders $\left(\chi^{2}=3.828, \mathrm{p} \geq 0.05\right)$.

The 10 years assessment of the individual risk of fatal cardiovascular diseases showed a low risk in 596 (56.6\%), moderate in 92 (8.7\%), high in $207(19.7 \%)$, and very high in $158(15.0 \%)$ patients. We observed a statistically significant risk difference in men $\left(\chi^{2}=163.974, p<0.001\right)$ (Table 3$)$, in patients aged 60 years and over $\left(\chi^{2}=338.799, p<0.001\right)$, smokers $\left(\chi^{2}=28.589, p<0,001\right)$, patients with poorly regulated hypertension $\left(\chi^{2}=278.881\right.$, $\mathrm{p}<0.001)$, diabetic patients $\left(\chi^{2}=35.574, \mathrm{p}<0.001\right)$, patients with metabolic syndrome $\left(\chi^{2}=57.805, \mathrm{p}<0.001\right)$, and in patients with increased total cholesterol $\left(\chi^{2}=17.489, \mathrm{p}<0,001\right)$.

In this sample there were only 32 (3.0\%) patients without risk factors for cardiovascular diseases, and $684(65.0 \%)$ patients had three or more risk factors. The number of risk factors was higher in the elderly $\left(\chi^{2}=67.370, p<0.001\right)$, while in both men and women there was no statistically significant difference as to the number of risk factors $\left(\chi^{2}=0.505, \mathrm{p}=0.777\right)$. The presence of risk factors is shown in Figure 1.

\section{DISCUSSION}

The malnutrition status, as a risk factor for many chronic diseases, is presented in this sample. The malnutrition indicates the increase of overweight people compared to the survey conducted in 2006 by the Institute of Public Health of Serbia (4). The cause is usually an unhealthy diet and physical inactivity, so the obesity and central fat accumulation may be a major risk factor for cardiovascular diseases $(5,6)$. We are concerned with a fact that overweight was more common in the elderly and in patients with hypertension and diabetes, which further increases the risk of cardiovascular diseases.

The smoking is associated with an increased risk of cardiovascular diseases in many studies $(7,8)$. The proportion of smokers (33.6\%) is similar to the study that was conducted in 2006 (4). 


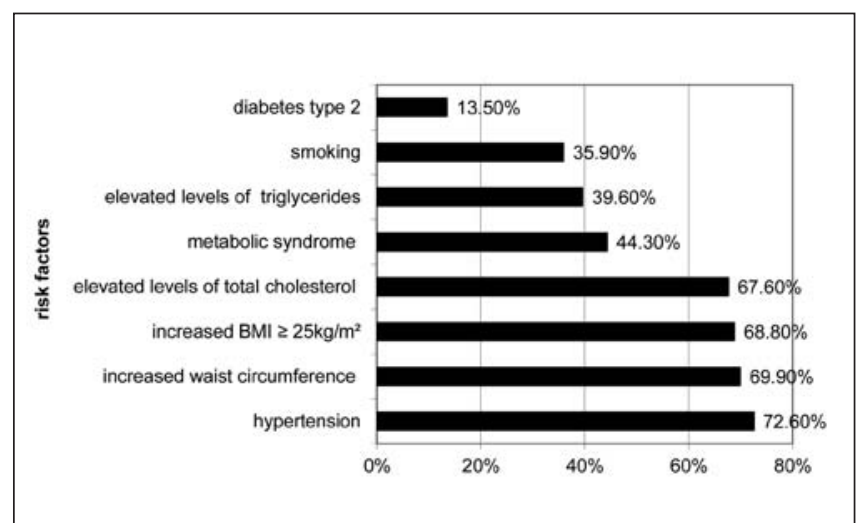

Fig. 1. Frequency of risk factors among patients.

Hypertension, which can be seen as a socio-medical problem, occurs in younger persons due to the mild and scarce symptoms, which often go undetected or discovered accidentally during the physical examination (9). The studies on this subject show that European countries have a higher incidence of this disease in comparison to other continents (10). The higher incidence of hypertension in this sample can be explained by the large number of older patients, smoking habits and malnutrition, while some studies suggest physical inactivity, alcohol consumption and the lack of education about hypertension (11-13). It is worrisome that $42.9 \%$ of respondents have a poorly regulated hypertension, whereas in other reports, this number goes up to $50 \%$ of patients $(10,14)$, which is usually conditioned by irregular treatment and the patient's lack of information about the disease. A very large number of poorly regulated blood tensions occurs among diabetics, which increases the risk for cardiovascular disease and the development of metabolic syndrome.

The prevalence of metabolic syndrome varies from $13.6 \%$ to $46 \%$ worldwide and is associated with increased cardiovascular comorbidity $(15,16)$. The data show that about $50 \%$ of hypertensive patients suffer from metabolic syndrome, which is confirmed by our study (9). Type 2 diabetes is a major risk factor for cardiovascular diseases because it causes micro and macrovascular complications that accelerate the process of atherosclerosis, and it is necessary to maintain a normal level of glucose in the blood, prescribed medical treatment and physical activity and proper nutrition (9).

Many epidemiological studies have confirmed the relationship between increased total cholesterol levels and the increased cardiovascular risk (17-19). In a survey conducted in 1996, the prevalence of lipid disorders in our country shows that the raised total cholesterol occurs in an average of $33.7 \%$ of patients (20). In our study, the increased levels of total cholesterol depict the trend in the prevalence of this disorder.

Going through the literature on the issue in other countries of the region, we come to the conclusion that there is a high rate of risk factors for cardiovascular diseases in the Balkan Peninsula. Results of the research conducted in Kosovo in 2011, noted that the prevalence rate of diabetes was $17.6 \%$ and $19 \%$ in Albania, which is a slightly higher rate than the one presented in our research $(21,22)$. The cause could be the elderly subjects (over 65 years of age) included in this research $(23,24)$, but also poor socio-economic and educational status. In the continental part of Croatia, among population from the urban areas, the nutritional status is of a similar structure to the one from our research. The same research discovered the presence of metabolic syndrome in $59.6 \%$ of patients, which is a slightly higher rate than in our research, while the ten year high risk (over 5\%) of fatal cardiovascular diseases appeared in $72.4 \%$ of examinees and this is double the results from our research. The ten year high risk occurred in $48.7 \%$ of examinees in the research conducted in Bulgaria (25). In the research published in Romania in 2010, the frequency of high blood pressure was $29.74 \%$, and joint high blood pressure and diabetes were found in $23.9 \%$ of examinees (26). The reason for such low occurrence of stated factors can be the age of examinees since the research included examinees aged from 14-90. In Croatia, 73.6\% of people with high blood pressure had metabolic syndrome and it is a higher rate than the one from our research (27).

It is necessary to evaluate the ten year risk of mortality from cardiovascular events in primary care, in order to identify persons who according to the short-term risk assessments require intensive therapy and therefore the model SCORE must be applied. This system is adapted to our region (1).

Because of the high prevalence of risk factors for cardiovascular diseases and a large number of patients with multiple risk factors, it is necessary to undertake more intensive preventive measures in order to reduce risk factors and promote and preserve health of the general population. These measures can include more frequent examinations of patients, patients' education and opening prevention centres for cardiovascular diseases.

\section{Conflict of Interests}

None declared

\section{Ethical Approval}

Health Centre Kragujevac Ethics Committee, No. 01-6391/3

\section{REFERENCES}

1. Republic Expert Commission for the development and implementation guides to clinical practice. Prevention of cardiovascular diseases. Belgrade: University of Belgrade, CIBID; 2004. (In Serbian.)

2. World Health Organization [Internet]. Geneva: WHO; 2011 [cited 2014 Sep 14]. Causes of death 2008. Available from: http://www.who.int/gho/ mortality_burden_disease/causes_death_2008/en/.

3. Prevention of cardiovascular disease: guidelines for assessment and management of total cardiovascular risk. Geneva: World Health Organization; 2007.

4. Knežević T, Grozdanov J, Vasić M. Health of population in Serbia - analytical studies 1997-2007. Beograd: Institute of Public Health of Serbia "Dr Milan Jovanovic Batut"; 2008. (In Serbian.)

5. Yusuf S, Hawken S, Ôunuu S, Bautista L, Franzosi MG, Commerford P; ; INTERHEART Study Investigators, et al. Obesity and the risk of myocardial infarction in 27000 participants from 52 countries: a casecontrol study. Lancet. 2005 Nov 5;366(9497):1640-9.

6. Dagenais GR, Yi Q, Mann JF, Bosch J, Pogue J, Yusuf S. Prognostic impact of body weight and abdominal obesity in women and men with cardiovascular disease. Am Heart J. 2005 Jan;149(1):54-60.

7. Maslennikova GY, Oganov RG. Impact of smoking on health of population in Russia and Europe. Profilac Zabol Ukrep Zdor. 2002;6:17-29.

8. Tanuseputro P, Manuel DG, Leung M, Nguyen K, Johansen H; Canadian Cardiovascular Outcomes Research Team. Risk factors for cardivascular disease in Canada. Can J Cardiol. 2003 Oct;19(11):1249-59.

9. Ostojic M, et al. Recommendations for prevention of ischemic heart disease. Beograd: National Committee for the development of clinical practice guidelines in Serbia; 2002. (In Serbian.) 
10. Guessous I, Bochud M, Theler JM, Gaspoz JM, Pechère-Bertschi A. 1999-2009 Trends in prevalence, unawareness, treatment and control of hypertension in Geneva, Switzerland. PLoS One. 2012;7(6):e39877.

11. Danon-Hersch N, Marques-Vidal P, Bovet P, Chiolero A, Paccaud F, Pécoud A, et al. Prevalence, awareness, treatment and control of high blood pressure in a Swiss city general population: the CoLaus study. Eur J Cardiovasc Prev Rehabil. 2009 Feb;16(1):66-72.

12. Tian S, Dong GH, Wang D, Liu MM, Lin Q, Meng XJ, et al. Factors associated with prevalence, awareness, treatment and control of hypertension in urban adults from 33 communities in China: the CHPSNE Study. Hypertens Res. 2011 Oct;34(10):1087-92.

13. Muntner P, Gu D, Wu X, Duan X, Wenqi G, Whelton PK, et al. Factors associated with hypertension awareness, treatment, and control in a representative sample of the chinese population. Hypertension. 2004 Mar;43(3):578-85.

14. Cutler JA, Sorlie PD, Wolz M, Thom T, Fields LE, Roccella EJ. Trends in hypertension prevalence, awareness, treatment, and control rates in United States adults between 1988-1994 and 1999-2004. Hypertension. 2008 Nov;52(5):818-27.

15. Salaroli LB, Saliba RA, Zandonade E, Molina Mdel C, Bissoli NS. Prevalence of metabolic syndrome and related factors in bank employees according to different defining criteria, Vitoria/ES, Brazil. Clinics (Sao Paulo). 2013 Jan;68(1):69-74

16. Lakka HM, Laaksonen DE, Lakka TA, Niskanen LK, Kumpusalo E, Tuomilehto J, et al. The metabolic syndrome and total and cardiovascular disease mortality in middle-aged men. JAMA. 2002 Dec 4;288(21):2709. 16.

17. Relationship of blood pressure, serum cholesterol, smoking habit, relative weight and ECG abnormalities to incidence of major coronary events: final report of the pooling project. The pooling project research group. J Chronic Dis. 1978 Apr;31(4):201-306.

18. Stamler J, Wentworth D, Neaton JD. Is relationship between serum cholesterol and risk of premature death from coronary heart disease continuous and graded? Findings in 356,222 primary screenees of the Multiple Risk Factor Intervention Trial (MRFIT). JAMA. 1986 Nov 28;256(20):2823-8.
19. Anderson KM, Castelli WP, Levy D. Cholesterol and mortality: 30 years of followup from the Framingham Study. JAMA. 1987 Apr 24;257(16):2176-80

20. Konstantinović D, Țigić D. Multicentre study of the prevalence of risk factors and chronic conditions. Gen Med J. 1996;2(3-3):83-127. (In Serbian.)

21. Jerliu N, Toçi E, Burazeri G, Ramadani N, Brand H. Prevalence and socioeconomic correlates of chronic morbidity among elderly people in Kosovo: a population-based survey. BMC Geriatr. 2013 Mar 1;13:22.

22. Ylli A. Health and social conditions of older people in Albania: baseline data from a national survey. Public Health Rev. 2010 Nov;32(2):549-60.

23. Espelt A, Borrell C, Roskam AJ, Rodríguez-Sanz M, Stirbu I, DalmauBueno A, et al. Socioeconomic inequalities in diabetes mellitus across Europe at the beginning of the 21st century. Diabetologia. 2008 Nov;51(11):1971-9.

24. Bergman Marković B, Vrdoljak D, Kranjčević K, Vučak J, Kern J, Bielen I, et al. Continental-Mediterranean and rural-urban differences in cardiovascular risk factors in Croatian population. Croat Med J. 2011 Aug 15;52(4):566-75.

25. Dyakova M, Shipkovenska E, Dyakov P, Dimitrov P, Torbova S. Cardiovascular risk assessment of Bulgarian urban population: cross-sectional study. Croat Med J. 2008 Dec;49(6):783-91.

26. Sur G, Sur M, Kudor-Szabadi L, Sur L, Sporis D, Sur D. Arterial hypertension - prevalence of risk factors and morbide associations that increase cardiovascular risk. Maedica (Buchar). 2010 Jan;5(1):34-40.

27. Ivezić-Lalić D, Bergman Marković B, Kranjčević K, Kern J, Vrdoljak D, Vučak J. Diversity of metabolic syndrome criteriain association with cardiovascular diseases - a family medicine-based investigation. Med Sci Monit. 2013 Jul 12;19:571-8

Received January 29, 2014

Accepted in revised form June 23, 2015 